\title{
Monitoria: uma modalidade de ensino que potencializa a aprendizagem colaborativa e autorregulada
}

Lourdes Maria Bragagnolo Frison*

DOI: 10.1590/0103-7307201607908

\section{Resumo}

Este artigo analisa se a monitoria, entendida como uma modalidade de ensino, potencializa a aprendizagem colaborativa e autorregulada dos estudantes universitários. Além do acompanhamento do trabalho de monitoria, desenvolvido em uma Insti* Universidade Federal de Pelotas (UFPel), Faculdade de Educação, Pelotas, RS, Brasil.lfrison@terra.com.br

tuição de Ensino Superior, durante um semestre letivo, realizouse uma entrevista semiestruturada com monitores e professores orientadores e aplicou-se um questionário com os universitários participantes das monitorias. Os dados coletados foram submetidos à análise de conteúdo, e seus resultados evidenciaram que $o$ trabalho realizado foi producente para a aprendizagem autorregulada de monitores e universitários, pois a maior parte desses estudantes aprendeu a utilizar diferentes estratégias de aprendizagem; e que a monitoria tende ao êxito nos espaços universitários, por investir na aprendizagem ativa, interativa, mediada e autorregulada.

Palavras-chave: monitoria, ensino, aprendizagem entre pares 


\title{
Monitorship: a teaching modality that enhances collaborative and self-regulated learning
}

\begin{abstract}
We sought in this article to examine whether monitorship, understood as a way of teaching, enhance collaborative and selfregulated learning of college students. The study was based on observation of the monitorship work conducted in an Institution of Higher Education, during one semester, semi-structured interviews with monitors and teachers and of a questionnaire answered by college students participating of the monitorship. The data were subjected to content analysis. The results of this analysis showed that the work done was productive for selfregulated learning of monitors and college students since most of the students learned to use different learning strategies. Monitorship thus tends to be a successful tool at the higher education level as it promotes active, interactive, mediated and self-regulated learning.
\end{abstract}

Keywords: monitorship, teaching, learning among pairs 


\section{Introdução}

O Ensino Superior depara-se, cada vez mais, com acadêmicos que apresentam dificuldades para atingir objetivos curricularmente prescritos, impostos pela necessidade de o aluno desenvolver competências e habilidades demandadas pelo mundo contemporâneo. Com certa frequência, as Instituições de Ensino Superior têm tido a preocupação de desenvolver projetos educativos e pedagógicos que envolvam acadêmicos oriundos de diferentes comunidades, visando ao aperfeiçoamento de sua qualificação.

Considera-se que o papel do Ensino Superior não é o de mero adicionador de conhecimentos teóricos e científicos. Ele é responsável por proporcionar a aprendizagem como um processo ativo, cognitivo, construtivo, significativo, mediado e autorregulado (Beltran, 1996), o que implica refletir sobre a organização de práticas pedagógicas e de metodologias de ensino.

É urgente ampliar o trabalho com diferentes propostas pedagógicas, investindo, quer no âmbito da docência, das aprendizagens e da avaliação, quer na gestão das instituições formadoras do Ensino Superior, para que se possa delas fazer verdadeiros instrumentos de intervenção, promotores do sucesso acadêmico de alunos, de professores e da própria instituição (Tavares, 2003). As Instituições de Ensino Superior (IES) buscam investir em estratégias e práticas que lhes permitam conquistar melhores resultados, tanto na avaliação do Ministério da Educação quanto no prestígio reverberado pelos egressos. Isso já constitui, por si só, motivo para investir em formas alternativas de trabalho, estimuladoras de aprendizagem, como é o caso das monitorias.

Nos diversos níveis de escolarização, continuam, porém, sendo adotadas práticas pedagógicas tradicionais, fundamentadas em concepções de aprendizagem que privilegiam a transmissão de conhecimentos. Essas abordagens configuram-se como “meras rotinas reprodutivas ... sem grande significado para o desenvolvimento das competências básicas e específicas que se pretende" (Tavares, 2003, p. 46). 0 professor trabalha os conhecimentos que domina e, mesmo que haja certa sintonia com os interesses dos alunos, por exemplo, quando esses conhecimentos se aproximam dos conhecimentos prévios dos alunos, sente dificuldade para perceber se eles estão aprendendo realmente. A maneira como o professor explica nem sempre é entendida por todos, e é praticamente impossível saber o que se passa na mente de cada um dos estudantes (Monereo, 2007). Nessa situação, o trabalho realizado em parceria 
entre professores e alunos ou entre os próprios alunos ganha força, principalmente no que diz respeito à monitoria. Pressupõe-se que ela pode contribuir para que todos os estudantes aprendam, pois se acredita que o modelo relacional e interativo estimula, de forma mais efetiva, o desenvolvimento das capacidades cognitivas.

É insuficiente, no entanto, implementar novas modalidades de trabalho, sem pensar sobre a necessidade de investir em diferentes estratégias de ensino e de aprendizagem. Isso leva a considerar que cabe aos docentes estimular o desenvolvimento de competências nos estudantes, para que obtenham uma aprendizagem mais significativa, efetiva e duradoura. Atualmente, fala-se, com mais frequência, na função reguladora da aprendizagem e na autorregulação da aprendizagem, devido à premência de a educação voltar-se para o desenvolvimento da autonomia e da compreensão do estudante, tornando-o capaz de planejar, executar e avaliar seu processo de aprendizagem (Rosário, Veiga Simão, Chaleta, \& Grácio, 2008).

Lopes da Silva, Duarte, Sá e Veiga Simão (2004) apresentam a autorregulação como uma ação dinâmica, temporal, intencional, planejada, complexa, mas que também depende das aspirações e das intenções, das competências e das estratégias, dos valores de cada estudante, de contextos e pressões sociais, cujos efeitos são resultado da interação de diferentes variáveis. Os aprendizes autorregulados são diferentes, pela visão que eles têm sobre a aprendizagem acadêmica: acreditam que aprender é uma atividade proativa e se destacam, entre seus colegas, pelas metas que estabelecem. Investem na promoção da escolha de estratégias que incrementem a qualidade de suas aprendizagens, na organização de um plano estratégico que possibilite vencer, cumprir as etapas planejadas (Zimmerman, 1998, 2013). Dentre as possibilidades de ensino que estimulam as aprendizagens dos acadêmicos, algumas se destacam: monitoria, tutoria, ensino colaborativo, portfólios. Esta investigação teve como foco explorar a monitoria no Ensino Superior.

\section{Monitoria: um pouco de sua história}

A monitoria teve seu início na Idade Média. O professor escolhia um assunto para ser defendido em público por alunos, que apresentavam seus argumentos sobre o tema escolhido. Os presentes ouviam atentos o debate, para depois questionar. Ao final do debate, o professor retomava o assunto tratado e apresentava sua argumentação.

Nos séculos XII e XIII, alguns dos mestres livres implantaram diferentes formas de gestão da atividade escolar, formando verdadeiras corporações. Em função disso, 
muitos progressos foram feitos. Na metade do século XIV, os mestres tinham quase sempre um "monitor", "repetidor" ou um proscholus, antigo nome latino atribuído às pessoas que os auxiliavam na escolarização. Na Inglaterra, esses mestres residiam junto com os estudantes, para dar aulas nas próprias moradias e cuidar melhor da disciplina. "Os estudantes dependiam das aulas para adquirirem informações, sendo que as mesmas eram ministradas em qualquer lugar, mesmo ao ar livre” (Giles, 1987, p. 85).

No século XVI, outra referência da monitoria provém dos jesuítas, que desenvolveram práticas de acordo com as regras contidas no Ratio Studiorum¹, porém, devido às rigorosas determinações, os jesuítas enfrentaram grandes desafios para se adaptar às exigências estabelecidas. Eles definiram uma didática bastante exigente e, para isso, passaram a receber auxílio dos melhores alunos, chamados “decuriões", responsáveis por outros colegas, de quem tomavam as lições de cor, recolhiam os exercícios e marcavam erros e faltas diversas (Miranda, 2009).

No século XVIII, há indícios do Método Monitorial de Lancaster na Inglaterra, promovido por leigos, denominado "ensino mútuo ou monitorial" 2 , no qual os adolescentes eram instruídos diretamente pelos mestres e atuavam como auxiliares ou monitores, ensinando, "por sua vez, outros adolescentes, supervisionando a conduta deles e administrando os materiais didáticos" (Manacorda, 1989, p. 256). A importância desse método está alicerçada fundamentalmente na atuação do monitor. Segundo Manacorda (1989), esse sistema de ensino minimizava as despesas de instrução, abreviava o trabalho do mestre e acelerava os progressos do aluno. Ele foi considerado um "sucesso porque abreviava o tempo despendido nas aprendizagens" (Lins, 1999, p. 77). Para Lesage (1999), o “agente de ensino no Método Mútuo é o aluno e o princípio fundamental desta prática consiste na reciprocidade de ensino entre os alunos” (p. 11). O mais capaz serve de professor, para auxiliar aquele que é menos capaz, caracterizando uma instrução simultânea, na qual todos avançam gradualmente, seja qual for o número de alunos. Surgiu, assim, a pedagogia do ensino mútuo.

O ensino mútuo expandiu-se para países de colonização espanhola no século XIX e foi muito utilizado, porque, “não podendo contar com mestres capacitados, a ideia era utilizar os melhores alunos - os monitores - para transmitir aos demais alunos os conhecimentos que haviam aprendido com o professor", instruía, assim, muitas pessoas em curto espaço de tempo (Bastos, 1999, p. 97). A implantação dessa prática educativa causou

1. Sobre a Ratio Studiorum, ver Miranda (2009). 2. Sobre o Ensino Mútuo, ver Lesage (1999). 
alvoroço, principalmente entre os franceses, porque instruía "até mil alunos com um só mestre" e oferecia instrução "elementar às classes inferiores a custos módicos" (Manacorda, 1989, p. 258). “Nos métodos individual e simultâneo, o agente de ensino é o professor. No método mútuo, a responsabilidade é dividida entre o professor e monitor, visando a uma democratização das funções de ensinar" (Bastos, 1999, p. 96). Ao monitor cabia auxiliar nas tarefas de ensinar a ler, escrever e calcular. Mesmo assim, não existia um programa único, cada instituição organizava as variações de acordo com suas necessidades. 0 ensino era apresentado ao grupo de alunos reunidos em função da matéria a ser ensinada.

A monitoria, portanto, "baseia-se no ensino dos alunos por eles mesmos" (Bastos, 1999, p. 97), tendo sido considerada uma das mais úteis invenções pedagógicas modernas, por reduzir em um terço ou mais o tempo gasto para a aquisição dos conhecimentos elementares, pois o "mestre supervisiona toda a escola e, especialmente, os monitores" (Manacorda, 1989, p. 259). Com essa amplitude, a monitoria acabou se expandindo por toda a América Latina³.

O uso de monitoria sempre foi uma estratégia utilizada em escolas unidocentes, cuja prática era atender, na mesma sala de aula, alunos da $1^{\mathrm{a}}$ à $5^{\mathrm{a}}$ série, pois, assim, os mais experientes ajudavam os que estavam cursando séries mais iniciais. No Ensino Superior, somente na década de 1960, com a Lei de Reformulação do Ensino Superior (Lei BR no 5540/68), é que se instituiu oficialmente a figura do monitor. 0 art. 41 determina que as universidades criem as funções de monitor para alunos do curso de graduação. Para se tornarem monitores, os candidatos devem ser submetidos a provas específicas, a fim de demonstrar capacidade de desempenho em atividades técnico-didáticas de determinada disciplina.

Nas universidades, principalmente nos cursos de Engenharias, Física, Matemática, devido aos altos índices de repetência, foi instituída a monitoria para trabalhar com alunos com dificuldades de aprendizagem, em atividades consideradas como aulas particulares em grupo (Bastos, 1999). As universidades faziam concurso para os candidatos inscritos ao cargo de monitor. Isto continua até hoje, "a monitoria vem ganhando espaços no contexto da realidade educacional das instituições de Ensino Superior à medida que demonstram resultados úteis e atenda as dimensões política, técnica e humana da prática pedagógica” (Candau, 1986, p. 12).

3. Sobre a expansão nos países latino-americanos, ver Bastos (2012).
A Lei de Diretrizes e Bases da Educação Nacional (Lei BR no 9.394, de 20 de dezembro de 1996) 
manteve essa função no Art. 84 , do qual se destaca a seguinte consideração: "os discentes da educação superior poderão ser aproveitados em tarefas de ensino e pesquisa pelas respectivas instituições, exercendo funções de monitoria, de acordo com seu rendimento e seu plano de estudos".

No ensino, as tarefas assumidas pelos alunos monitores têm como objetivo auxiliar o professor titular, mas, nos cursos superiores, a monitoria tem sido utilizada, com muita frequência, como estratégia de apoio ao ensino, especialmente para atender estudantes com dificuldades de aprendizagem. Percebe-se, em sua aplicabilidade, que ela conserva a concepção original, pela qual os estudantes mais adiantados nos programas escolares auxiliam na instrução e na orientação de seus colegas.

Respaldada em lei, essa estratégia, prevista nos regimentos das instituições e nos projetos pedagógicos institucionais, pode potencializar a melhoria do ensino de graduação, mediante a atuação de monitores em práticas e experiências pedagógicas, em disciplinas que permitam articulação entre teoria e prática e integração curricular. Visa também oportunizar ao graduando atitudes autônomas perante o conhecimento, assumindo, com maior responsabilidade, o compromisso de investir em sua formação. A monitoria tende a ser representada como uma tarefa que solicita competências do monitor para atuar como mediador da aprendizagem dos colegas, contando, para sua consecução, com a dedicação, o interesse e a disponibilidade dos envolvidos (Batista \& Frison, 2009). Nessa perspectiva, o monitor atua como orientador e organizador das propostas de ensino, quer em pequenos grupos, quer em atividades com a turma toda.

\section{Contexto da pesquisa e campo metodológico}

A pesquisa aqui relatada foi realizada em uma Instituição Particular de Ensino Superior (IES), em uma cidade do Rio Grande do Sul, de março a junho de 2012, e teve como corpus monitores, estudantes participantes das monitorias e professores orientadores de disciplinas que tinham monitoria nos cursos das Licenciaturas em Letras, Matemática e Pedagogia.

Analisou-se, nesta pesquisa, a forma como a monitoria é utilizada para potencializar a aprendizagem colaborativa e autorregulada dos estudantes universitários. Com tal finalidade, adotou-se a pesquisa exploratória, que teve, como instrumentos de coleta de dados, entrevistas semiestruturadas com monitores e professores orientadores e um questionário aplicado aos estudantes participantes das monitorias. 
Os sujeitos da pesquisa foram 9 monitores, sendo 3 de cada curso (número de monitores definido por curso, pela IES, no semestre em que a pesquisa foi realizada); 9 professores orientadores (professores responsáveis por cada uma das disciplinas contempladas com monitores); 28 estudantes que participaram como aprendizes das monitorias, dos quais apenas 15 compareceram a todos os encontros e responderam os questionários. Portanto, o número de questionários respondidos refere-se aos estudantes que nunca faltaram.

A entrevista semiestruturada realizada com monitores continha perguntas relacionadas ao trabalho que faziam, às dificuldades percebidas, aos avanços que o monitor percebia em sua aprendizagem e na aprendizagem do estudante aprendente, ao tipo de orientação recebida dos professores, às exigências e às responsabilidades relacionadas à função de monitor. As perguntas dirigidas aos professores orientadores tinham como foco entender a sistemática e a regularidade das orientações fornecidas, os resultados das orientações feitas aos monitores e as dificuldades encontradas. Por serem entrevistas semiestruturadas, muitas perguntas surgiram à medida que transcorria o relato dos monitores ou dos professores orientadores.

Aos estudantes participantes das monitorias foi aplicado, ao final do semestre, um questionário contendo perguntas abertas e fechadas que intencionavam saber como eles avaliavam o trabalho, principalmente o que tinham aprendido na monitoria. As perguntas abertas questionavam sobre aspectos positivos e dificuldades encontradas, se houvera aprendizagem dos conteúdos, se o colega conseguira explicar e tirar dúvidas, se utilizara diferentes estratégias de ensino. Nas perguntas fechadas, o estudante marcava com um ' $X$ ' a alternativa (muito, pouco, nada) que melhor explicitava seu ponto de vista.

Os dados coletados foram submetidos à análise de conteúdo, que conduziu a descrições sistemáticas, qualitativas, para reinterpretar as mensagens e atingir a compreensão de seus significados em um nível que vai além de uma leitura comum, sendo orientada por modelos teóricos propostos por Bardin (1977) e Almeida e Freire (2000), uma vez que apresentam aspectos de análise comuns entre si: (a) pré-análise dos dados; (b) exploração do material; (c) tratamento dos resultados, inferência e interpretação.

Para melhor compreensão dos dados obtidos na pesquisa, foram inseridos, neste artigo, alguns excertos dos depoimentos dos monitores, dos estudantes envolvidos e dos professores orientadores. Além disso, apresentam-se, na sequência, dois quadros, contendo indicadores das respostas dos estudantes. Os depoimentos dos pro- 
fessores orientadores estão identificados como $\mathrm{P}_{1}, \mathrm{P}_{2}$ até $\mathrm{P}_{9}$; os depoimentos dos monitores, como M1, M2 até M9; os dos estudantes, como E1, E2 até E15.

\section{Condições da IES na atuação dos monitores}

Ao iniciar a análise dos resultados, ressalta-se que seis dos nove monitores já tinham atuado como monitores no semestre anterior, o que, segundo seus próprios depoimentos, contribuiu para qualificar o trabalho realizado, uma vez que já sabiam como deveriam agir e fazer. Realça-se que, na instituição investigada, para se tornarem monitores, os estudantes devem atender ao prescrito no edital de seleção: ter cursado a disciplina na qual desejam ser monitores; ter obtido, no mínimo, média oito e meio nas disciplinas nas quais pretendem ser monitores; disponibilizar tempo para o desempenho da função. Os acadêmicos, ao se inscreverem para a seleção, têm conhecimento de que deverão realizar uma entrevista e prestar uma prova escrita. Ao ingressarem na função de monitor, recebem isenção de pagamento proporcional às horas de exercício nessa função. Ao final de cada semestre letivo, é exigida a apresentação de relatórios sistemáticos à direção e à coordenação de curso.

Conforme os objetivos propostos no edital da monitoria da instituição pesquisada, o programa de monitoria busca motivar os estudantes a obter melhores resultados na aprendizagem, estimulando-os a participar das monitorias, tanto desenvolvendo atividades de ensino, como elegendo diferentes estratégias de ensino. Na instituição investigada, a monitoria foi oferecida, às terças e às quintas-feiras, em horários que antecediam o período de aulas, sendo livre a adesão do estudante a essa atividade, Nessa instituição, a monitoria é definida como instrumento que contribui para a meIhoria do ensino e da aprendizagem, considerando os estudantes de graduação.

\section{Análise e discussão dos resultados}

Dos dados analisados emergiram indicadores que foram organizados em três blocos distintos. 0 primeiro contém os depoimentos e os indicadores dos monitores que investiram nas monitorias. Essa categoria foi denominada $O$ que pensam e fazem os monitores. O segundo bloco de análise se refere aos depoimentos dos professores responsáveis pelas monitorias. A categoria foi definida como $O$ que relatam os professores orientadores das monitorias. No terceiro bloco, mostram-se as percepções dos estudantes que participaram das monitorias. A categoria foi definida como 0 que dizem os estudantes participantes das monitorias. 


\subsection{0 que pensam e fazem os monitores}

$\mathrm{Na}$ análise das respostas às perguntas abertas, formuladas aos monitores, encontram-se indicadores de que o trabalho feito por eles foi producente: os nove monitores envolvidos disseram que tiveram resultados favoráveis no decorrer do seu trabalho. Afirmaram que, enquanto estudavam para ensinar, aprendiam. Dos nove, sete monitores relataram que aprenderam a selecionar diferentes estratégias para ensinar os conteúdos da disciplina pela qual eram responsáveis e que o trabalho que faziam envolvia debates, pesquisas e encontros sistemáticos com o professor orientador. Somente dois monitores apresentaram restrições às monitorias, justificando a falta de experiência, pois, como estavam sendo monitores pela primeira vez, tiveram muitas dificuldades para orientar o grupo. Um deles (M9) destacou que o professor orientador nem sempre podia investir esforços para ajudá-lo, devido às múltiplas tarefas que tinha. Apesar disso, os nove monitores destacaram que houve avanços tanto na aprendizagem dos estudantes envolvidos como na própria aprendizagem. Afirmaram que, para obter sucesso na monitoria, tiveram que aprender a estabelecer metas, a buscar ajuda com interesse intrínseco ao conteúdo, o que promoveu a automonitorização das estratégias, as quais, adaptadas ao grupo, desencadearam autorreações positivas. Ratificando essa percepção, o monitor $\left(M_{2}\right)$ destacou que a aprendizagem entre colegas foi fundamental, porque um ajudou o outro com aquilo que sabia. Esse estudante lembrou que a monitoria não pode, contudo, substituir o estudo individual, nem as aulas ministradas pelo professor. Semelhante observação encontra-se nos resultados das pesquisas de Lopes da Silva, Veiga Simão e Sá (2006) e de Monereo (2007), quando apresentam estratégias de ensino que contribuem para o aprofundamento dos estudos acadêmicos, argumentando serem elas uma instância complementar ao que o professor ensina em sala de aula.

Nos depoimentos dos monitores, percebeu-se forte preocupação com a aprendizagem compreensiva, “definida como aprendizagem profunda”, destacada em pesquisa publicada por Duarte (2002, p. 25). Para o monitor (M5), aprender e ensinar se imbricam: "ensinar é trocar conhecimentos". "Essa troca se dá por um princípio dialético - aprende-se na interação com o outro" (Vygotsky, 1995). A concepção dialética abarca as dimensões relacional e pessoal, o que fortalece a dialética da participação (Bidell, 1992). Ressalta-se que os monitores não ministraram aulas, mas sistematizaram, organizaram, ensinaram estratégias com as quais os estudantes regularam a aprendizagem dos conteúdos já ensinados pelos professores em sala de aula. As 
estratégias ensinadas aos estudantes abrangiam as dimensões cognitivas/metacognitivas, motivacionais e comportamentais.

As cognitivas/metacognitivas dizem respeito ao pensar e ao aprender, se referem ao conhecimento que o estudante tem sobre seus processos cognitivos (memória, compreensão) e influenciam a forma como cada um regula seu processo de aprendizagem. Montalvo e Torres (2004) assinalam que os estudantes precisam saber aplicar estratégias cognitivas (repetição, elaboração, organização) para que possam organizar, elaborar e recuperar a informação. Precisam também planejar, controlar e dirigir seus processos mentais para atingirem metas pessoais (metacognição). As estratégias motivacionais contribuem para que o estudante mova esforços para aprender, mas, para isso, precisa definir objetivos e ter motivos para os atingir. A motivação é necessária para que o estudante tenha persistência na realização de suas tarefas e supere os obstáculos que surgirem. As comportamentais são as que auxiliam a controlar o tempo, a organizar o material e o local de estudos, a solicitar ajuda dos mais experientes, quando necessário.

Os monitorres definiram metas, estabeleceram objetivos e refletiram como, quando e onde utilizar os diferentes tipos de estratégias, encaminhando ajustes quando necessário. É preciso destacar que a premissa que acompanhou esse processo foi a de que o conhecimento se constrói na medida em que o sujeito é provocado a desenvolver competências, podendo com elas autorregular e controlar sua ação. Isso significa que não basta apenas promover espaços de reflexão e apreensão de conhecimento, se as aprendizagens não forem sistematizadas pelo próprio sujeito.

Considerando tudo isso, a atividade de monitoria é vista por oito, dos nove monitores, como um espaço que promoveu a reflexão, uma vez que se utilizaram diferentes estratégias para estimular os estudantes a revisar e a aprofundar os conteúdos curriculares trabalhados nas disciplinas.

Essa prática foi considerada adequada para atingir melhores resultados ao término do semestre. 0 monitor (M7) explicou: “Isso acontece não porque sou responsável direto por fazer atividades para os estudantes entenderem o conteúdo, mas porque as experiências proporcionadas entre colegas, que falam a mesma linguagem, apresentam as mesmas dificuldades, estimulam o aprender". Os monitores, segundo depoimento de sete deles, afirmaram terem contado com a dedicação, o interesse, a disponibilidade e a ajuda dos professores orientadores, o que permitiu que avançassem na escolha das estratégias, mobilizando-os para ensinar e aprender. 


\subsection{0 que relatam os professores orientadores das monitorias}

A entrevista com os professores orientadores teve como foco entender como o trabalho dos monitores e das monitorias era feito: se a orientação ao monitor era sistemática ou eventual, se havia planejamento e como o trabalho acontecia. Além disso, buscou-se saber como foi a participação dos monitores e se houve avanços em suas aprendizagens.

Ao analisar as entrevistas, percebeu-se que nem todos os professores tinham sistemáticas semelhantes. Sobre esse fato, os nove professores orientadores afirmaram que são múltiplas as formas que encontram para dar orientação aos monitores, algumas a distância (por e-mail), outras presenciais. Todas, porém, aconteceram sistematicamente ao longo do semestre. No entanto, dois professores afirmaram que os encontros de orientação aconteceram com mais intensidade quando os monitores precisaram de ajuda. A totalidade de professores orientadores destacou que os encontros variam: alguns são breves, outros mais longos, e a maior preocupação centra-se no cuidado sobre os conteúdos e as atividades a serem trabalhadas. Explicitam que, nos encontros, foram também discutidas diferentes estratégias de ação e exercícios de sistematização. Uma das estratégias bastante salientada foi a busca de ajuda perante alguma dificuldade na tarefa de aprendizagem. Segundo Serafim e Boruchovitch (2010), a estratégia de pedir ajuda é a mais utilizada pelos estudantes, quando se deparam com alguma dificuldade. 0 pedido de ajuda é importante para lidar com situações de dificuldade, principalmente quando o estudante consegue determinar, conscientemente, que ela se faz necessária. Segundo os professores, eles não só investiram na qualificação das ações dos monitores no que se refere ao uso de estratégias, como também indicaram estudos teóricos necessários ao bom andamento da monitoria. Tal fato foi confirmado por sete dos nove monitores investigados. Apenas dois expressaram que precisariam de mais ajuda e acompanhamento.

Dentre os professores orientadores, sete dos nove envolvidos afirmaram que a monitoria requer supervisão e orientação sistemática, em especial nas atividades que dizem respeito ao ensino. A totalidade dos professores assinalou que o monitor precisa, de igual forma, se preparar, estudar, organizar suas estratégias para auxiliar os demais estudantes. Os docentes acreditam que a monitoria possibilitou aos envolvidos conhecer o que não conheciam e dominar o que não dominavam. Para isso, o professor orientador colocou o monitor diante de diferentes situações e dificuldades, levando-o a se envolver e a estudar. 


\subsection{0 que dizem os estudantes participantes das monitorias}

No contexto geral, verificou-se um alto índice de assiduidade dos estudantes que participaram das monitorias: 15 deles revelaram nunca terem faltado. Isso indica que o trabalho realizado na monitoria os ajudou a melhorar o grau de compreensão em suas aprendizagens. Essa ajuda centra-se na utilização das estratégias aprendidas pelo aluno, como: (a) estratégias cognitivas/metacognitivas - possibilitam aprender a: organizar-se e tomar consciência das demandas exigidas pelas tarefas propostas, resolver as situações desafiadoras, avaliar os procedimentos escolhidos e os resultados alcançados; (b) estratégias motivacionais - auxiliam na compreensão das razões para mover esforços para aprender (o que se quer e aonde se quer chegar) e ajudam a lidar melhor com o sucesso e o fracasso, com a ansiedade e com as possíveis desmotivações; (c) estratégias comportamentais - envolvem controlar o tempo, organizar o material e o local de estudo, solicitar ajuda aos mais experientes (Lopes da Silva, Duarte, Sá, \& Veiga Simão, 2004).

Ratificou-se, portanto, a relevância da monitoria, a qual não se refere ao ensino explícito do conteúdo, mas à aprendizagem, ao uso das diferentes estratégias para potencializar o aprender. Os estudantes disseram que o trabalho realizado em pequenos grupos revelou a verdadeira aprendizagem, um estudante ajudando o outro. Percebeu-se que houve maior empenho em fazer as tarefas e dedicação a elas com mais afinco quando os encontros antecediam as provas. Isso mostra o quanto o estudante ainda procrastina as tarefas acadêmicas, sublinhando-se que a procrastinação não é um traço de personalidade, mas um comportamento influenciado por situações ambientais. A não realização ou o atraso no desenvolvimento das atividades pode “prejudicar o desempenho acadêmico e o próprio processo de autorregulação da aprendizagem, acredita-se ser pertinente compreender a natureza da relação entre a autorregulação da aprendizagem e a procrastinação acadêmica" (Sampaio, Polydoro, \& Rosário, 2012, p. 181). Mesmo assim, os 15 estudantes que participaram do grupo sistematicamente dizem que houve envolvimento, estímulo, ajuda e incentivo dos monitores, para que pudessem refletir sobre seus objetivos e expectativas, o que promoveu a responsabilidade pessoal e o comprometimento com a aprendizagem e com o estudo. Houve progresso nos estudos, cada qual fazendo suas reflexões, a partir do diálogo estabelecido com a ajuda do grupo e dos monitores. À luz da teoria vygotskyana, acredita-se que a monitoria atua em duplo movimento: intra e interpsicológico. 
O interpsicológico é caracterizado pelo envolvimento do eu na relação com os outros, configurando as ajudas recíprocas. 0 intrapsicológico é caracterizado pelas escolhas que cada sujeito faz diante da proposta de trabalho. Sendo assim, há forte envolvimento subjetivo de cada um nas tarefas de aprendizagem (Vygotsky, 1995). Um dos estudantes (E11) escreveu: "graças às ajudas que recebi, pude melhorar muito em meus estudos". Afirmação semelhante é destacada por Onrubia (2001), quando afirma que os estudantes, ao receberem ajuda, "mostram-se progressivamente competentes e autônomos na resolução de tarefas, na utilização de conceitos, na prática de determinadas atitudes" (p. 23).

Em vários depoimentos, os estudantes ressaltaram fatos que, segundo eles, foram importantes para organizar e melhorar seus estudos, por exemplo: "o monitor me ajudou a examinar criticamente a matéria" (E6); ajudou-me "a destacar as ideias principais e as subjacentes" (E7); "a estabelecer hierarquia nas tarefas e atividades a serem feitas" (E1); "a evitar coisas que me distraíssem e que me atrapalhavam na hora de estudar" (E15); "a criar roteiros de trabalho" (E11); "a conhecer e discutir os diferentes pontos de vista” (E9); “a gestar melhor meu tempo de estudo” e "a evitar os distratores" (E13).

Infere-se que a monitoria tenha ajudado na obtenção de "maior segurança no assunto estudado" (E7) e que "serviu de aprendizado para descobrir outras formas para aprender" (E3). A afirmativa mais recorrente dos 15 estudantes mostra que foram ajudados a debater sobre os conteúdos, a antever suas metas, a prever os obstáculos, a realizar um planejamento para aprender os conteúdos da disciplina. Conforme um dos monitores ( $\mathrm{M} 2$ ), muitos estudantes, ao iniciarem o trabalho de monitoria, colocavam-se em uma condição "adversa”, rendiam-se antes mesmo de iniciar a tarefa ou respondiam às primeiras tentativas de intervenção, dizendo um desconcertante "não sei fazer". Daniels (2003) expõe que a "produção de artefatos culturais pela atividade colaborativa talvez intensifique a autorreflexão e leve ao desenvolvimento metacognitivo" (p. 63). Segundo sete dos nove monitores, superar as resistências e vencer os distratores thes possibilitou progredir na aprendizagem.

Nas perguntas fechadas do questionário, as respostas dos estudantes que participaram da monitoria evidenciam que esta proposta contribuiu para o enfrentamento das dificuldades, estimulando a aprendizagem dos conteúdos e das estratégias, o que os ajudou a aprender. As respostas às perguntas sobre as atividades realizadas na monitoria foram tabuladas e estão registradas nos Quadros 1 e 2. Os números de 
alunos inseridos na tabela foram calculados a partir das respostas ao questionário, dadas pelos 15 estudantes envolvidos.

Quadro 1: Processos autorregulatórios desencadeados nas monitorias

\begin{tabular}{|l|c|}
\hline Indicadores & Número de alunos \\
\hline Melhorei minha comunicação com os colegas & 14 \\
\hline Venci a timidez e participei efetivamente & 12 \\
\hline Enfrentei minhas dificuldades de aprendizagem & 12 \\
\hline Investi em minhas possibilidades & 15 \\
\hline Estudei muito mais do que venho estudando & 12 \\
\hline Investi na compreensão dos textos e ou conteúdos & 14 \\
\hline Planejei melhor as tarefas que tenho que fazer & 13 \\
\hline Controlei/gastei melhor o tempo para realização das tarefas & 13 \\
\hline $\begin{array}{l}\text { Percebi quais os conteúdos em que tenho mais dificuldade } \\
\text { e pedi ajuda }\end{array}$ & 14 \\
\hline Tive notas melhores do que as que tinha antes da monitoria & \\
\hline
\end{tabular}

Fonte: Frison (2012)

Ao analisar as respostas, percebeu-se que, dos 15 estudantes participantes das monitorias, 12 disseram que investiram em suas possibilidades e 13 revelaram dificuldades na aprendizagem. Os dados mostraram que todos estudaram e se envolveram nos estudos, bem mais do que vinham fazendo até então. Segundo eles, houve avanços, inclusive, nos resultados das avaliações das disciplinas. No entanto, o que ainda parece ser bem complicado é evitar os distratores. Conforme os percentuais expressos no Quadro 2, somente 8 estudantes, praticamente metade dos respondentes, conseguiram evitá-los. Isso pode explicar por que os estudantes procrastinam suas tarefas de estudo. Parece haver falta de consciência e controle, no que se refere à tomada de decisão, quando a questão está relacionada ao tempo destinado ao estudo. Pode haver outras explicações e justificativas para esse fato, mas a mais frequentemente apresentada por eles se refere à falta de controle no uso do computador. Os estudantes verbalizaram que as redes sociais tiram muito tempo do estudo, o que explica que somente 9 deles conseguiram evitar a procrastinação. Um deles (E10) explicitou: “Evitar as redes sociais é super complicado". Conforme registrado no 
Quadro 2, com a participação dos estudantes nas monitorias, diminuíram as faltas em sala de aula, os alunos foram mais pontuais, motivaram-se para o estudo, aproveitando melhor o tempo.

Quadro 2: Mudanças reveladas no percurso da monitoria

\begin{tabular}{|l|c|}
\hline Indicadores & Número de alunos \\
\hline Faltei menos aulas & 15 \\
\hline Fui mais pontual & 13 \\
\hline Estive mais motivado, com mais vontade de estudar & 12 \\
\hline Aproveitei mais o tempo & 14 \\
\hline Estudei mais & 12 \\
\hline $\begin{array}{l}\text { Dediquei-me, fora da monitoria, para entender melhor o } \\
\text { assunto }\end{array}$ & 15 \\
\hline $\begin{array}{l}\text { Aprendi muito mais nesta disciplina do que nas que não } \\
\text { tinham monitoria }\end{array}$ & 8 \\
\hline Tentei evitar os distratores (redes sociais, etc.) & 9 \\
\hline Procrastinei minhas tarefas de estudo & \\
\hline
\end{tabular}

Fonte: Frison (2012).

\section{Reflexões sobre os achados da pesquisa}

Ao refletir sobre os depoimentos coletados em relação aos avanços, verifica-se que a monitoria oportunizou, tanto para os monitores quanto para os estudantes, terem atitudes autônomas perante o conhecimento, impulsionando-os à responsabilidade e ao compromisso com a própria aprendizagem. Do que foi dito pela totalidade dos envolvidos na pesquisa (professores, estudantes e monitores), infere-se que a monitoria é uma proposta de trabalho que solicita competências do monitor para atuar como mediador das aprendizagens; investe nas possibilidades que cada estudante tem para aprender; fortalece os professores orientadores a continuarem abrindo oportunidades para que os estudantes potencializem sua aprendizagem.

Pelos indicadores aqui apresentados, evidencia-se que as práticas de monitoria são muito importantes. Elas facilitam o processo de aprender, ajudando a superar problemas, bloqueios, pressões, dificuldades internalizadas que limitam a aprendizagem. Os achados relativos às características da monitoria ressaltam o acompanha- 
mento dos estudantes em seus tempos, ritmos e avanços, nas dificuldades pessoais e coletivas.

Os estudantes aprenderam na relação com o outro, ativados por objetivos compartilhados, que se alternaram, (re)configuraram, conforme as estratégias propostas no processo estabelecido. 0 professor orientador, atento e disponível, que acompanhou o processo, oportunizou melhores condições para que a monitoria acontecesse. 0 trabalho de monitoria pode contribuir para a aprendizagem, principalmente, de quem tem mais dificuldade de entender a explicação do professor, de quem precisa de um tempo maior para exercitar-se nas atividades propostas e para compreender o conteúdo. Destaca-se que não houve, durante a pesquisa, depoimentos desfavoráveis à aula ministrada pelo professor, nem havia intenção de averiguá-la.

A análise das respostas evidenciou indicadores de que o trabalho foi profícuo, pois estudantes e monitores investiram nos encontros e atingiram sua meta: a aprendizagem. Conversar, discutir, pensar coletivamente foram ações que se multiplicaram, possibilitando o entendimento dos conteúdos. A conversa, o debate, a troca de ideias contribuíram para mudar o pensar, o sentir e o agir dos envolvidos (Osório, 2003). A monitoria desencadeia um processo de construção de autonomia, controle e consciência para o sujeito e para o grupo (Anastasiou \& Alves, 2006).

Infere-se que a monitoria oportunizou "aumento da eficiência na aprendizagem" (E11), “aumento da motivação” (E14) e "aceleração da aprendizagem” (E15). Nas palavras dos monitores: “também aprendi ao ensinar" (M4); “descobri que posso aprender mais se me dedicar" (M5). Compreende-se, portanto, que a proposta de monitoria é significativa e se define justamente na forma como é ministrada e no comprometimento dos envolvidos.

\section{Considerações finais}

Este texto apresentou o resultado de uma pesquisa exploratória sobre monitoria, desenvolvido em uma instituição particular de Ensino Superior, oferecendo elementos para entender o significado de sua adoção e sua importância para a área educacional. Os achados advindos da investigação sobre monitoria sugerem que o desenvolvimento da consciência, do controle, da gestão do tempo, da organização das tarefas é essencial para a promoção da aprendizagem. Tais achados indicam que o fundamental para os estudantes foi ultrapassar o plano das aprendizagens baseadas na memorização de conteúdos e atingir o plano das aprendizagens conscientes, 
intencionais e estratégicas, as quais foram trabalhadas na monitoria. Ao final, os envolvidos apresentaram desempenhos positivos, mais autônomos e comprometidos em relação à sua aprendizagem.

Os dados da pesquisa indicam que, na monitoria, não só o professor ensinou e produziu pensamento crítico, orientando os monitores, mas também os estudantes e os monitores aprenderam juntos, sistematizando diferentes pontos de vista. Essas conclusões mostram que a proposta de ensino monitorial possibilita a construção de uma aprendizagem baseada na consciência e no autocontrole.

Inadvertidamente se poderia pensar que a monitoria é uma modalidade de ensino fácil; porém, ao contrário, ela é uma prática exigente, que requer acompanhamento e cuidado constantes na formação e na qualificação dos monitores e muito empenho dos professores orientadores. No Ensino Superior, assumir essa proposta pedagógica pode trazer avanços para a aprendizagem dos estudantes. 


\section{Referências bibliográficas}

Almeida, L., \& Freire, T. (2000). Metodologia da investigação em psicologia da educação. Braga: Psiquilíbrios.

Anastasiou, L. G. C., \& Alves, L. P. (2006). Estratégias de ensinagem. In L. G. C. Anastasiou, \& L. P. Alves (Orgs.), Processos de ensinagem na universidade: pressupostos para as estratégias de trabalho em aula (pp. 67-100). Joinville, SC: UNIVILLE.

Bastos, M. H. C. (1999). O ensino mútuo no Brasil (1808-1827). In M. H. C. Bastos, \& L. M. de Faria Filho (Orgs.), A escola elementar no século XIX (pp. 95-118). Passo Fundo: Ed. UPF.

Bastos, M. H. C. (2012). A instrução pública e as independências na América Latina: as experiências lancasterianas no século XIX. In A. L. S. Reckziegel, \& A. Heinsfeld (Orgs.), Estados americanos: trajetórias em dois séculos (p. 19-44). Passo Fundo: Ed. Universidade de Passo Fundo.

Bardin, L. (1977). Análise de conteúdo. Lisboa: Ed. 70.

Batista, J. B., \& Frison, L. M. B. F. (2009). Monitoria e aprendizagem colaborativa e autorregulada. In D. Voos, \& J. B. Batista (Orgs.), Sphaera: sobre o ensino de matemática e de ciências (pp. 232-247). Porto Alegre: Premier.

Beltran, J. (1996). Concepto, desarrollo y tendencias actuales de la Psicología de la instrucción. In J. Beltran, \& C. Genovard (Eds.), Psicología de la instrucción: variables y procesos básicos (v. 1 pp.19-86). Madrid: Síntesis/Psicología.

Bidell, T. (1992). Beyond interactionism in contextualist models of development. Human Development, (35), 306-315.

Candau, V. M. F. (1986). A didática em questão e a formação de educadores-exaltação à negação: a busca da relevância. In V. M. F. Candau (Org.), A didática em questão (pp. 12-22). Petrópolis: Vozes.

Daniels, H. (2003). Vygotsky e a Pedagogia. São Paulo: Ipiranga.

Duarte, A. M. (2002). Aprendizagem, ensino e aconselhamento educacional: uma perspectiva cognitivo-motivacional. Porto: Porto Ed.

Giles, T. R. (1987). História da Educação. São Paulo: EPU.

Lesage, P (1999). A pedagogia nas escolas mútuas do século XIX. In M. H. C. Bastos, \& L. M. de Faria Filho (Orgs.), A escola elementar no século XIX: O método monitorial (pp. 09-35). Passo Fundo: Ediupf.

Lins, A. M. M. (1999). O método Lancaster: educação elementar ou adestramento?

Uma proposta para Portugal e Brasil no século XIX. In M. H. C. Bastos, \& L. M. de Faria Filho (Orgs.), A escola elementar no século XIX (pp. 73-94). Passo Fundo: Ediupf. 
Lopes da Silva, A., Duarte, A. M., Sá, I., \& Veiga Simão, A. M. (2004). Aprendizagem auto-regulada pelo estudante: perspectivas psicológicas e educacionais. Porto: Porto Editora.

Lopes da Silva, A., Veiga Simão, A. M., \& Sá, I. (2006). A auto-regulação da aprendizagem: estudos teóricos e empíricos. Intermeio, (19), 58-74

Manacorda, M. A. (1989). História da educação: da antiguidade aos nossos dias. São Paulo: Cortez.

Miranda, M. (2009). Código pedagógico dos jesuítas: Ratio Studiorum da Companhia de Jesus. Campo Grande: Esfera do Caos.

Monereo, C. (2007). Aprender entre iguais e com iguais. In D. Duran, \& V. Vidal (Orgs.), Tutoria: aprendizagem entre iguais. Porto Alegre: Artmed.

Montalvo, F. T., \& Torres, M. G. (2004). El aprendizaje autorregulado: presente y futuro de la investigación. Revista Electrónica de Investigación Psicoeducativa, 2(1), $1-34$.

Onrubia, J. (2001). Ensinar criar zonas de desenvolvimento proximal e nelas intervir. In C. Coll (Org.), Construtivismo na sala de aula. São Paulo: Ática.

Osório, L. C. (2003). Psicologia grupal: uma nova disciplina para o advento de uma era. Porto Alegre: Artmed.

Rosário, P., Veiga Simão, A. M., Chaleta, E., \& Grácio, L. (2008). Auto-regular o aprender em sala de aula. In M. H. M. B. Abrahão (Org.), Professores e alunos: aprendizagens significativas em comunidades de prática educativa (pp.115-132). Porto Alegre: EDIPUCRS.

Sampaio, R., Polydoro, S., \& Rosário, P. (2012). Autorregulação da aprendizagem e a procrastinação acadêmica em estudantes universitários. Cadernos de Educação, (42), 119-142.

Serafim, T., \& Boruchovitch, E. (2010). O pedir ajuda: concepções dos estudantes do ensino fundamental. Estudos interdisciplinares em Psicologia, 1(2), 159-171.

Tavares, J. (2003). Formação e inovação no Ensino Superior. Porto: Porto Editora.

Vygotsky, L. S. (1995). Pensamento e linguagem. São Paulo: Martins Fontes.

Zimmerman, B. J. (1998). Developing self-fulfilling cycles of academic regulation: an analysis of exemplary instructional models. In D. H. Schunk, \& B. J. Zimmerman, Self-regulated learning: from teaching to self-reflective practice (pp.1-19). New York: The Guilford Press.

Zimmerman, B. J. (2013). From cognitive modeling to self-regulation: a social cognitive carrier path. Educational Psychologist, 48(3), 135-147. 


\section{Legislação}

Decreto-Lei $B R n^{\circ} 5.540$, de 28 de novembro de 1968. Fixa normas de organização e funcionamento do ensino superior e sua articulação com a escola média. Retirado em 10 de junho de 2012 de <http://www.planalto.gov.br/ccivl_03/Leis/>5540.htm>. Lei $B R n^{\circ}$ 9.394, de 20 de dezembro de 1996. Estabelece as diretrizes e bases da educação nacional. Ministério da Educação. Conselho Federal de Educação. Retirado em 10 de junho de 2012, de «http://www.planalto.gov.br/ccivl_03/Leis/>9394.htm>.

Submetido à avaliação em 15 de abril de 2015; aceito para publicação em 25 de maio de 2015 . 
